\title{
Analysis and Design a Safeguard For Bike Rider Using Embedded System
}

\author{
R.Sangeetha, Dr.Ramkumar prabhu ${ }^{2}$ \\ ${ }^{1}$ UG Scholars, Department of ECE, Apollo Engineering College, Chennai. \\ ${ }^{2}$ Professor, Department of ECE, Apollo Engineering College, Chennai.
}

\begin{tabular}{lll}
\multicolumn{3}{l}{ Article Information } \\
Received & 18 April 2020 \\
Revised $\quad:$ & 19 May 2020 \\
Accepted $\quad:$ & 04 June 2020 \\
Published $\quad:$ & 14 June 2020
\end{tabular}

Corresponding Author:

R. Sangeetha

Email:ramkumarprabhu@gmail.com

\begin{abstract}
The objective is to provide a resources and devices for detecting and recording collusion between bikes. Sensors and cloud computing infrastructures are utilized for building system. The collision detection system communicates the accelerometer values to the processor which continuously monitors for erratic variations. When the collision occurs, the information's are passing to the concern by using a cloud-based service. GPS is used for identifying the location of the bike. The application of this system is extended to smart cities and smart helmets.
\end{abstract}

Keywords: Location identification, SOS messages, smart phones, search and rescue, wireless networks.

Copyright @ 2020: R.Sangeetha. This is an open access distribution, and reproduction in any medium, provided Access article distributed under the Creative Commons Attribution License the original work is properly cited License, which permits unrestricted use.

Citation: R.Sangeetha, Dr.Ramkumar Prabhu. "Analysis and Design a Safeguard For Bike Rider Using Embedded System, "Journal of Science, Computing and Engineering Research, 1(2), 58-60, May-June 2020.

\section{INTRODUCTION}

The thought of emerging this paper comes from social responsibility towards the civilization. According to a survey, around 750 people die in road accidents occurring due to bike bangs per year. The reason for the accidents may be many such as no proper driving knowledge, damaged bikes, rash driving, drunk and drive etc. But the major reason was found to be the absence of helmet on that person's head resulting in an instant death due to brain damage. In this system, we use ARDUINO UNO (ATmega328P) microcontroller which acts as brain of the system, because the entire system program instruction stored in it. Here we have two section in which one is at the helmet and the other is at the vehicle. The helmet section has touch sensor which gives the information about the status of whether the helmet is occupied or not, also we have sensors like gyroscope and vibration sensor to know the status of accident. The location of accident area along SMS have done by the GSM module we have. All the data fetched from the helmet section is transferred through RF technology and Reception take place at the vehicle section. Eye blink sensor in this concept is used to alert the driver if he is in drowsiness condition. LDR which detects the light intensity, gives the values to the controller, which automatically adjusts the brightness of the light according to the light intensity.

\section{RELATED WORKS}

Judos A, Vybhavi R, and Anusha b proposes a mechanism by using a parameter such as gas sensors, Zigbee, IR sensor load sensor for accident detection location-based ambulance is booked automatically[1]. Sayan tapadar, arnab kumar Saha, Dr. Himadrinath Saha, with help of internet and android phone the system can identify the accident and it can send the notification message to registered contact person. [2],[3] Sudhir Rao rupanagudi, sumakha Bharadwaj Varsha G. and Vikram subrahmanya, Fathima jabeen discuss a novel methodology used to two wheelers in avoiding rear and collision.[4] Prashant Ahuja, prof ketan bhavasar discuss a microcontroller based. Smart helmet using GSM and GPRS. [5] G. Vishnu, V. Kishore swami proposed a GSM based system which can encourage the importance of helmet for life saving to human beings. [6] Mohd Khairul Afid Mohd Rasli, Nina korlina, Juliana joharu moniter the force sensing resistance, and BLDC fan, LM311 and IC555 to detect helmet and speed of motor detection. [7] Amruth Madhusan suggests the system which aims at reducing the loss of people lives in road accidents and perform accident detection.[8] Yi-Jen Mon explains the Gyroscope Sensor testing by using Arduino Platform. [9] Luayfraiuan Then khaldonLeesy deliberate the wireless 
safety device foe gas leakage detection using gas sensor. [10] Ravi Kishore kodali and Adilya Valdas, the paper dicuss ESP8266 Wi-Fi chip enabled microcontroller nodeMCO.and smoke sensor, ultrasonic sensor.

\section{METERIALS AND APPROACHES}

\section{A. Microcontroller (Atmega 328p)}

Atmega 328p is acting as CPU for this system with high operating speed. The space requirements very less it will be fixed compact inside the helmet. Operating frequency of this controller is about $16 \mathrm{MHZ}$ with analog and digital input ports. Atmega can receive signal from sensors and it will take appropriate control action.

\section{B. Accelerometer (AXDL335)}

This type of sensor to identify the acceleration of the bike which is acting one of the input to microcontroller. This is operating in 3 (X, Y and $\mathrm{Z}$ ) direction with bandwidth of first two axes are $1600 \mathrm{HZ}$ and next two axes are about $550 \mathrm{HZ}$.

\section{Touch Sensor}

Touch sensors will working based on touch i.e applied pressure. The mechanism behind this sensor is switching operation (open and close). Switch will close when touching the sensor because the pressure is applying, if not switch will open. Based on the sensor can give output.

Principle of touch sensors are like capacitors contains parallel plated separated by insulating material.

\section{Eyeblink Sensor}

Eye blink sensors working based on infrared by blinking can be identified in eyelid area with help of variable resistance device. If the eye position is open or close the output will be either high or low.

When eye didn't blink means open position the output of the sensor is low and vice versa. Then the output is given to one of the input to microcontroller to take control action by giving alarm to bike rider.

\section{E. Vibration Motor}

Vibration motor gives vibration operating based on the control signal given by microcontroller. A linear resonant actuator (LRA) gives a pressure in terms of force to the bike rider to give attention

\section{F. Crash Sensor}

Crash sensor which helps to identify when the bike rider met with an accident. This accidents occurs this sensor will be enables and output of the sensor will be electrical signal in nature sent to microcontroller.

\section{G. Gas Sensor}

Generally gas sensor are sensing multi parameter like atmosphere gases, temperature and alcohol in breathe. This sensors can operate the temperature range of -20 to $45^{\circ} \mathrm{C}$. The sensing range is from $0.04 \mathrm{mg} / \mathrm{L}$.

\section{H. LDR}

A Light Dependent Resistor working based on light. When the light available it can be detect and the same will be converted in to resistance. This signal will be given to controller. Behind LDR principle the change in resistance due to applied input .

\section{Zigbee}

Zibee is an IEEE 802.15.4- is a kind wireless communication between the different sensors which is involve in the application. These Zigbees are communicating in between 10 to 12 meters with $2.4 \mathrm{GHz}$ band.

\section{J.GPS}

GPS is a satellite navigation system used to determine the ground position of an object. To identify the object of human exact location GPS are playing critical role.

\section{K.GSM}

Global system for mobile communication (GSM) is a globally accepted standard for digital cellular communication. GSM/GPRS Modem-RS232 is built with Dual Band GSM/GPRS engine- SIM900, works on frequencies 900/ $1800 \mathrm{MHz}$.. These commands are called as AT commands, there are a list of AT commands to instruct the modem to perform its functions. When a ten-digit mobile number is provided, the program instructs the modem to send the text message using a sequence of AT commands.

\section{Speed Sensor}

It is used to measure the speed of object generally called as tacho meters. The speed can be identified based on the revolution takes place with respect to time. It given in terms of RPM.

IV. WORKING PRINCIPLE

In this system, we use ARDUINO UNO (ATmega328P) microcontroller which acts as brain of the system, because 
the entire system program instruction stored in it. Here we have two section in which one is at the helmet and the other is at the vehicle.The helmet section has touch sensor which gives the information about the status of whether the helmet is occupied or not,if the rider wont wear the helmet the inigation of the bike is off ,rider wont to strats up the vehicle without wearing the helmet.And also we have sensors like gyroscope and crash sensor. to know the status of accident.

The location of accident area along SMS have done by the GSM module we have. All the data fetched from the helmet section is transferred through RF technology and Reception take place at the vehicle section. Eye blink sensor in this concept is used to alert the driver if he is in drowsiness condition.LDR which detects the light intensity, gives the values to the controller, which automatically adjusts the brightness of the light according to the light intensity.hence this project helps to decreses the death rate in road accident. And it will also helps to crop , they wont to tested if the rider involves drank and drive and helmet wearing case.they wont to put any fine amount to the riders who where not wearing the helmet.

\section{Hardwaresetup}

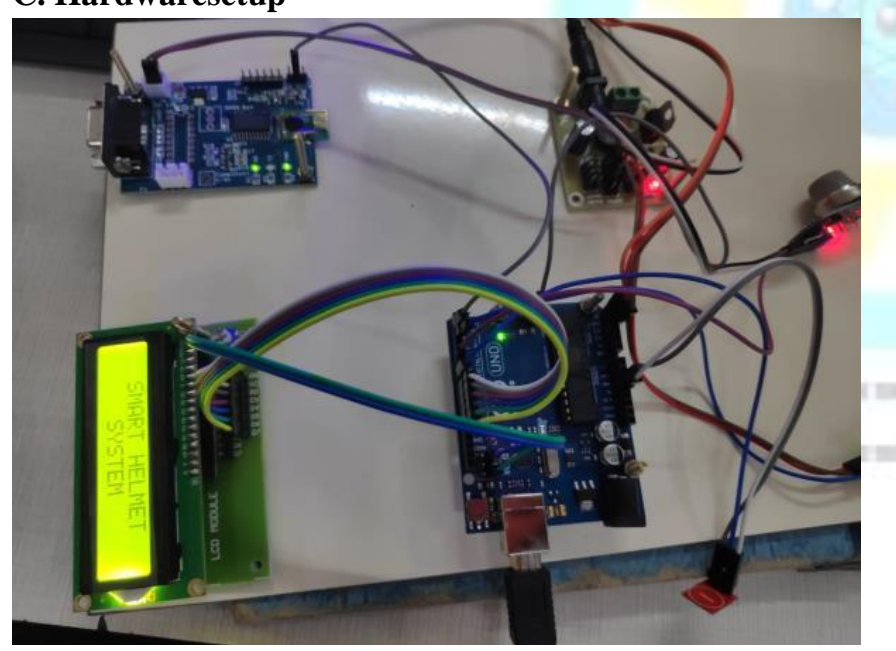

Figure 1Helmet section

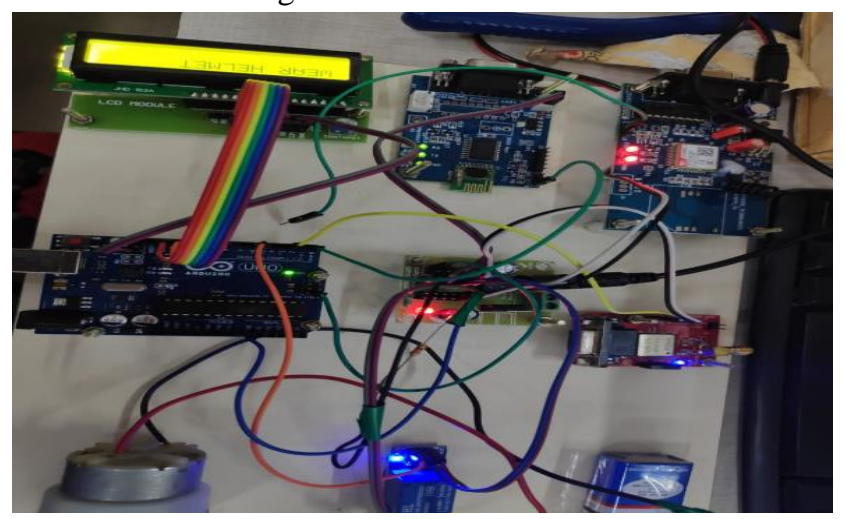

Figure 2Vehicle section

\section{CONCLUSION}

The two wheeler safety system developed with helmet and smart bike system is reliable and purposes to help in the prevention, detection and reporting of accidents to decreses the death rate and hence reducing the probability of drunk and drive cases. This system detects the incidence of an accident and makes provisions to sound an alert through the use of a GPS and GSM system. It aims in providing a low cost, mainly focusing on the importance of human life.

\section{REFERENCES}

[1] Hartwell, Peter G., and James A. Brug. "Smart helmet." U.S. Patent No. 6,798,392. 28 Sep. 2004

[2] Parada, Rita, et al. "Helmet-based navigation notifications." U.S. Patent No. 9,146,124. 29 Sep. 2015.

[3] Manjesh N, Prof. Sudarshan Raj, "Smart Helmet Using GSM \&GPS Technology for Accident Detection and Reporting System", International Journal of Electrical and Electronics Research, Vol. 2, Issue 4, October December 2014

[4] Rasli, Mohd Khairul Afiq Mohd, Nina Korlina Madzhi, and Juliana Johari. "Smart helmet with sensors for accident prevention." Electrical, Electronics and System Engineering (ICEESE), 2013 International Conference on. IEEE, 2013

[5] Sahs, Himadri nath, Abhilasha mandal and abhirup Sinha. Sayan tapor "accident and alcohol detection in Bluetooth enabled smart helmets for motorbikes

[6]Vishnu.Kishoreswaminathan,V.Vishwanth,K.Srinivasan,"Accid ental identification and navigation system in helmet,2017 International Conference on Nextgen Electronic Technologies.

[7] Mohd Khairul Afiq Mohd Rasli, Nina Korlina Madzhi Juliana Johari, Smart helmet with sensor for accident Identification and navigation system in helmet, 2017 ICNETS2.

[8]Muthiah M ,Aswin Natesh V ,Sathiendran R K, Smart helmets for automatic control of headlamps, International Conference of Smart SENSORS and Systems. 